\title{
Technique for aerosol generation with controllable micrometer size distribution
}

\author{
Yao-Chuan Lee ${ }^{\mathrm{a}, \mathrm{b}, *}$, Fu-Tien Jeng ${ }^{\mathrm{a}}$, Chih-Chieh Chen ${ }^{\mathrm{c}}$ \\ ${ }^{a}$ Graduate Institute of Environmental Engineering, National Taiwan University, Taipei 10617, Taiwan \\ ${ }^{\mathrm{b}}$ Department of Safety Health and Environment, Tungnan University, Taipei, 22202, Taiwan \\ ${ }^{\mathrm{c}}$ Institute of Occupational Medicine and Industrial Hygiene, National Taiwan University, Taipei 10051, Taiwan
}

\section{A R T I C L E I N F O}

\section{Article history:}

Received 27 February 2008

Received in revised form 9 June 2008

Accepted 10 June 2008

Available online 3 August 2008

\section{Keywords:}

Aerosol generator

Ultrasonic atomizer

Size distribution pattern

Test aerosol

\begin{abstract}
A B S T R A C T
The purpose of this study is to develop an aerosol generating system that can produce particles of micrometer size in a convenient and efficient way. This system is comprised of an ultrasonic atomizer, potassium sodium tartrate tetrahydrate (PST) as solute and a program-controlled solute feeding unit with different PST concentrations. Both the aerosol concentration and size distribution pattern can be easily controlled and reproduced in the developed system. While the initial size of droplets generated from atomizer may remain unchanged, the size of residual dry aerosols was controlled by the solute concentration adjusted by the mixing ratio of solute and water. In addition, PST concentration could be alternatively adjusted in any cyclic way to provide particles with relatively mono-disperse, bimodal, varying size as well as skew distribution to meet requirements for various applications. The main advantage of the generating system is to generate particles of specific size distribution in order to simulate aerosols in ambient air or working places.
\end{abstract}

(c) 2008 Elsevier Ltd. All rights reserved.

\section{Introduction}

Size distribution is one of the most important characteristics of aerosol. Most concerned issues about aerosol are related to the size of the particles, e.g., respiratory health effect, features of particle sources, removing efficiency of different mechanisms, visibility reduction, among others. The health effects of atmospheric particles have been studied extensively including mass concentration, size and ingredients of particles. Some epidemiological researches have shown that the adverse effects of fine particles are important (e.g., Oberdorster et al., 1995; Peters et al., 1997). However, larger particles contribute more to mass contribution because mass is proportional to cubic power of diameter. The deposition fraction of inhaled coarse particles in the respiratory tract significantly differs from that of fine particles. The health effect caused by particles of micrometer size is still important in at least some locations (Smith et al., 2000).

Conventional mass concentration monitoring data are inadequate to evaluate health risk of these particles. Consequently, the development of real-time measuring instruments for particle size distribution is of importance. The results can provide means to investigate atmospheric aerosol size distributions and potential health effects under various conditions (Shi et al., 2001; Vette et al., 2001; Wehner et al., 2002; Zhu et al., 2002). Furthermore,

\footnotetext{
* Corresponding author. Address: Department of Safety Health and Environment, Tungnan University, Taipei 22202, Taiwan. Tel./fax: +8862 23625946.

E-mail address: d89541008@ntu.edu.tw (Y.-C. Lee).
}

particle removal efficiencies of air pollution control devices are highly related to the size of particles. Thus, it is necessary to develop some devices that can simulate the particle size distribution to evaluate the efficiency of particle control device (Endo et al., 1998), entrainment effect of particulate from floor-level into the breathing zone of a human (Heist et al., 2003), or performance evaluation of different measuring instruments (Pagel's et al., 2005). As a result, any system which can generate aerosol particles of specified size distribution should be useful in the evaluation of both health effects and particle removal performance.

A test aerosol generator for providing different sizes of aerosols with reproducibility, reliability, durability and stability is essential. The factors to be considered when choosing an appropriate generator include size range, generation frequency, size distribution pattern and convenience. Many aerosol generation methods have been developed, including atomization of liquid, atomization of liquid containing suspended particles, dispersion of powders, vaporization-condensation, pulsed spark discharge and chemical reaction methods (Hinds, 1999; Park et al., 1999; Baron and Willeke, 2001; Veranth et al., 2003; Kim and Chang, 2005). Under most conditions the size distribution of environmental particles and particles generated by above mechanisms are log-normal. By controlling the operating conditions, it is possible to change particles size distribution from log-normal to non-log-normal distribution by agglomeration growth (Weigle et al., 2004). Unfortunately, none of them could easily control the desirable particle size distributions, e.g., only in either mono- or poly-disperse size without changing the composition of the aerosol source. Further, few 
devices can generate bimodal size distribution (e.g., Park et al., 1999; Nichols et al., 2002). This is important since the bimodal size distribution is often observed in atmospheric environment, e.g., nearly bimodal distribution was polycyclic aromatic hydrocarbons with two and three rings with mean diameter $<2 \mu \mathrm{m}$ (Zhou et al., 2005). For example, an ultraviolet-laser ablation method was developed to generate bimodal size distribution particle with a smaller mode peaked at $50-70 \mathrm{~nm}$ and a larger mode at 0.70 $0.85 \mu \mathrm{m}$, but the applied laser power could only change the number concentration but not the particle size (Lee and Cheng, 2006).

Consequently, this study was undertaken to develop a novel system to generate aerosol with either mono-disperse aerosol or bimodal size distribution in micron size. More importantly, the method developed provides an easy and straightforward way for generating desirable size in a short time scale, unlike the previous tedious methods. The conventional atomization of liquid was chosen for aerosol generation. The uniqueness of the developed system lies in two feeding tubes; one contains the potassium sodium tartrate tetrahydrate ( $\mathrm{PST}, \mathrm{KNaC}_{4} \mathrm{H}_{4} \mathrm{O}_{6} \cdot 4 \mathrm{H}_{2} \mathrm{O}$ ) solution and the other tube carries pure water. By changing the flow distribution between these two solutions, the PST concentration can be easily adjusted resulting in different mono-disperse aerosol sizes with relatively smaller geometric standard deviation (GSD). Fur- ther, by varying the PST concentration alternatively or cyclic adjustment of PST concentration, the bimodal size could be easily obtained. The factors evaluated included the total liquid feeding rate, power level of the ultrasonic atomizer and mixing length. It is our belief that the generated unimodal or bimodal size can be effectively used for a variety of functions, including health risk analysis and particulate removal evaluation.

\section{Materials and methods}

\subsection{Aerosol generating system}

The PST was selected as an aerosol precursor compound to produce the desirable particle sizes. The schematic diagram of the system is shown in Fig. 1. To facilitate the adjustment of PST solute concentration of the feeding liquid in different ways, two programmable syringe pumps (model KDS 200P, KD Scientific) were used to deliver both the solute solution and water in any desirable fractions to the respective stainless needles (each $0.5 \mathrm{~mm}$ OD and $0.1 \mathrm{~mm}$ ID) which were inserted into the nozzle of an ultrasonic atomizer (Model 8700-60, Sonotek Inc., St. Paul, MN). The distance for the mixing zone for these two liquids can be adjusted, up to $8 \mathrm{~mm}$; thereafter, the liquid mixture is atomized in the chamber

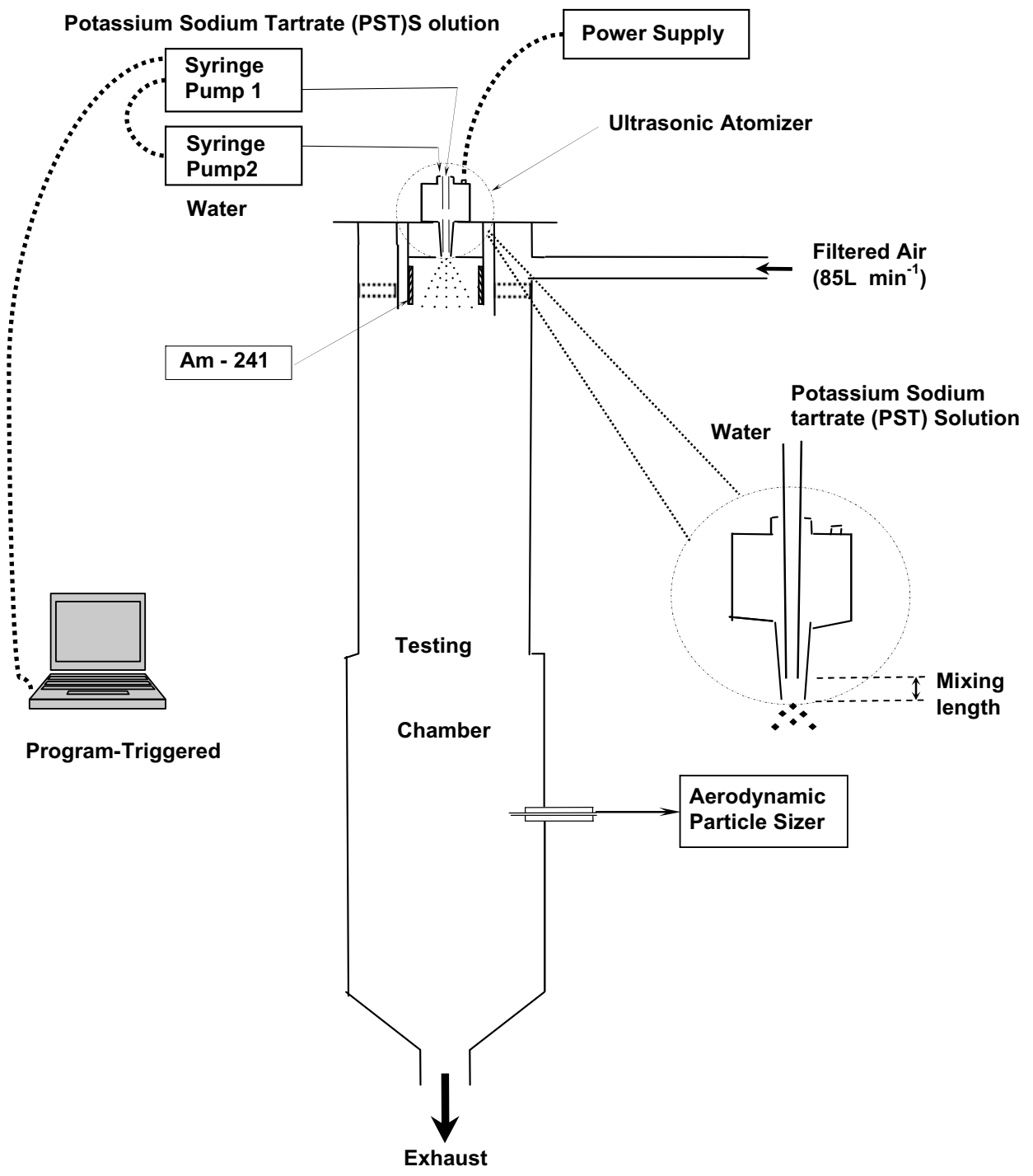

Fig. 1. Schematic diagram of the aerosol generating system and testing facilities. 
(13 cm diameter, $140 \mathrm{~cm}$ height). The concentrations of the PST in the mixed liquid can be easily adjusted by the flow rates of the two pumps. The communication ports of two pumps were connected to a personal computer through the built-in RS232 interface. The pumps were then triggered independently and simultaneously by a steering program in Microsoft Visual Basic 6.0.

The droplets generated in the acrylic testing chamber were then diluted and dried by almost "dry" filtered air to form target residues. The "dry" air with relative humidity $(\mathrm{RH})$ about $5 \%$ was prepared by air compressor and cryogenic dehumidifier. A $10 \mathrm{mCi}$ Americium-241 (Am-241) radioactive source was applied to neutralize the charge of the generated aerosols near the atomizer nozzle. The size-resolved number concentration of aerosols, measured at the downwind end of the testing chamber, was continuously monitored by an Aerodynamic Particle Sizer (APS, Model 3310, TSI Inc.). Humidity and temperature in the testing chamber were simultaneously measured by humidity/temperature indicator and probe (sensor: Hygro Clip SL05, data logger: HygroLog, Rotronic Inc.).

\subsection{Experimental method}

The feeding rate of syringe pumps, programmed by a computer, was arranged in two different ways, either a single step for a constant PST concentration or a cyclic step by adjusting the flow distribution of two liquids. The symbol $1.0 \mathrm{C}$ refers to the use of only PST $(1.05 \%)$ and $0.1 C$ represents the mixed liquid consisting of $90 \%$ water and $10 \%$ PST solution resulting in $0.105 \%$ PST level. For all tests, the total feeding rate from both water and PST solutions remained constant at $0.5 \mathrm{ml} \mathrm{min}{ }^{-1}$. For example, $0.01 \mathrm{C}$ indicates that the flow rates injected from PST solution and water were 0.005 and $0.495 \mathrm{ml} \mathrm{min}^{-1}$, respectively, or PST concentration of $0.0105 \%$. For example, for a cycle of $20 \mathrm{~s}$, the atomizer was fed with $0.01 \mathrm{C}$ concentration during the $1 \mathrm{st} 10 \mathrm{~s}$, with the next $10 \mathrm{~s}$ of the only PST solution (1C). For the latter cyclic ways to generate desirable aerosol sizes, the PST concentration was adjusted alternatively in many cycles; each cycle lasted 20-30 s. However, the total feeding rate to the atomizer nozzle in each step remained unchanged to provide a steady generation rate of droplets. The measuring time for APS was set as an integral multiple of the cyclic time of generation system. Average size distribution of the aerosol generated was acquired within this measuring time; thus with a cycle of $20 \mathrm{~s}$, average data included three sets of results from different PST concentrations when the measuring time was set as $1 \mathrm{~min}$.

The factors evaluated included power level of the atomizer, total liquid feeding rate and mixing length. The dry air flow rate and PST concentration in the PST reservoir remain constant, at $851 \mathrm{~min}^{-1}$ and $1.05 \%(\mathrm{v} / \mathrm{v})$, respectively.

\section{Results and discussion}

\subsection{Stability of the system}

Initially, it was necessary to verify if the particle number concentrations of the sample were steady during the entire period of the test. During the stability test of injection only different PST solutions without supply of additional stream of ultrapure water, the sampling time of APS was set at $20 \mathrm{~s}$, shorter than the setting for subsequent tests to improve the time resolution. The aerosol concentration showed an initially rapid increase once the atomizers was triggered for aerosol generation. Due to the traveling time of the dilution air $\left(85 \mathrm{l} \mathrm{min}^{-1}\right)$ from top of the chamber to the sampling point $100 \mathrm{~cm}$ downstream, the particle number concentration became rather stable after $40 \mathrm{~s}$ of the initiation of the test. The coefficient of variation $1.2 \%$ observed indicates that the overall system including mixing is satisfactory. It is also noted that a relatively lower number concentration (ca. $200 \mathrm{~cm}^{-3}$ ) is observed due to low PST liquid injection rate (only $0.6 \mathrm{ml} \mathrm{min}^{-1}$ ).

\subsection{Optimized power}

A wide range of flow rate as well as power level at the same constant PST concentration (1.05\%) was used to test the effectiveness of the ultrasonic atomizer. The particle size distributions with GSD and peak diameter, mode $\left(d_{\mathrm{p}}\right)$, results of five tests are shown in Fig. 2. Several points in Fig. 2 data need to be emphasized. Firstly, all these systems regardless of liquid rates and power levels could generate aerosols of approximately the same size (ca. $7.8 \mu \mathrm{m}$ ) when powers were less than $3 \mathrm{~W}$, since the PST concentration is the same $(1.05 \%, v / v)$. When the powers were larger than $3 \mathrm{~W}$, the mode diameter will gradually decrease at all liquid flow rates. Secondly, there appears an optimum power level around $3 \mathrm{~W}$ on the variation of GSD. Below or above $3 \mathrm{~W}$, the GSD of particles increases. The exact reason(s) is unclear; too little/much lower would change the size distribution. Thirdly, the effect of liquid flow rate on the variation of GSD depends on power input; the lowest rate $\left(0.3 \mathrm{ml} \mathrm{min}^{-1}\right)$ yields the least GSD. Finally, the particle

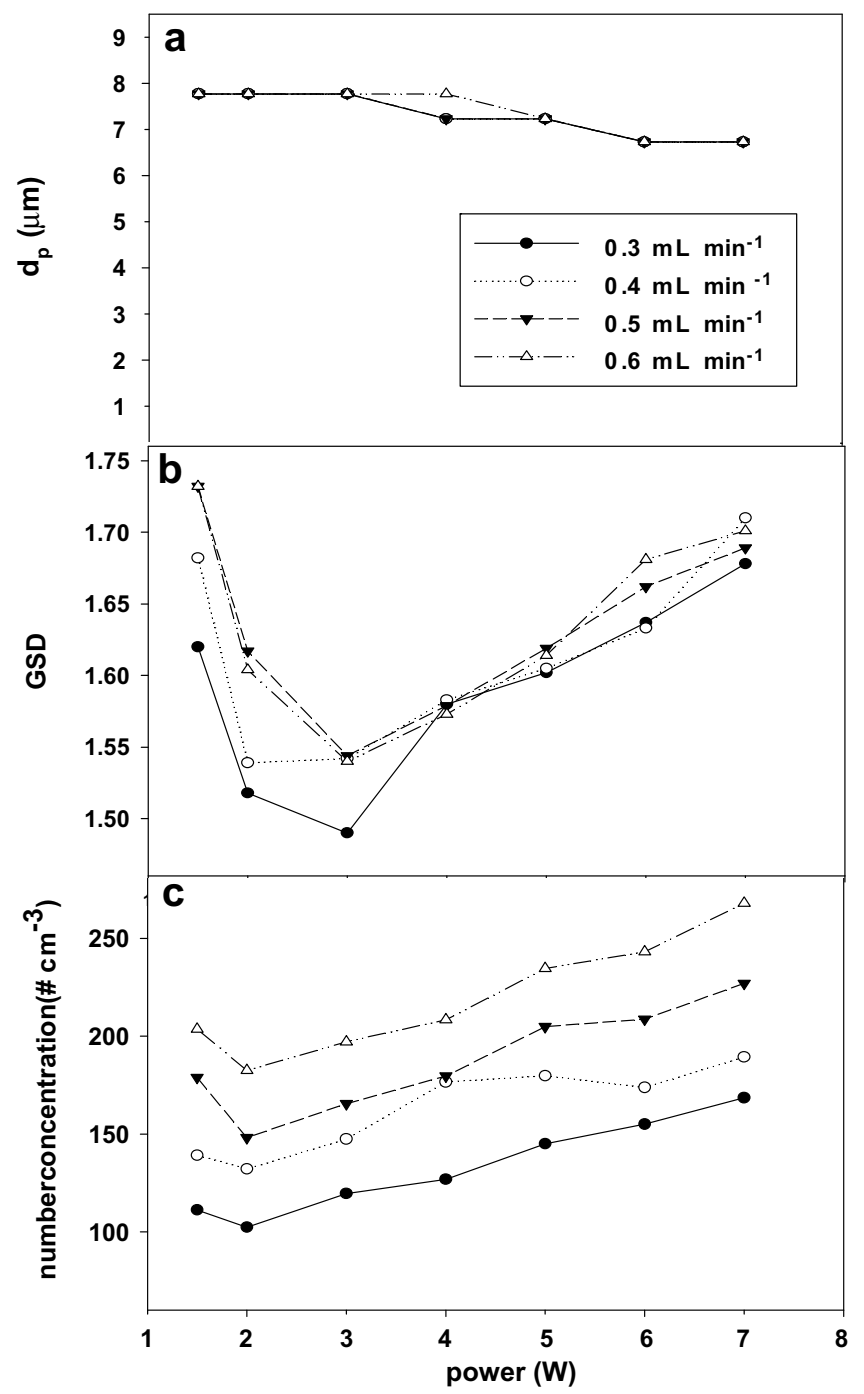

Fig. 2. Mode $\left(d_{\mathrm{p}}\right)$, geometric standard deviation (GSD) and number concentration variation at different power input and feeding rate. Injection liquid, PST 1.05\% (v/v); dilution air $85 \mathrm{ml} \mathrm{min}^{-1}$. 
concentrations increase with liquid injection rate. Since the particle size of aerosols generated did not change appreciably at different liquid flow rates, the number concentrations of the aerosol should increase with higher liquid flow rates. Further, the particle concentrations increase with the power level $>2 \mathrm{~W}$.

\subsection{Humidity change}

Water evaporation of droplets in the presence of the dry dilution air would reduce the size of aerosols, which caused humidity in the chamber to increase. A series of experiments with varying water injection rates (from 0.1 to $0.7 \mathrm{ml} \mathrm{min}^{-1}$ ) were performed by monitoring the humidity variation to account for the mass of water evaporation in the chamber and thus to ensure that the aerosols were "fully dried". The temperature in the chamber would be lower at higher liquid rates and the calculation was performed to ensure the conservation of water mass (Table 1). For water droplets less than $50 \mu \mathrm{m}$ in diameter, the drying time in $50 \% \mathrm{RH}$ of air was less than $1 \mathrm{~s}$ (Hinds, 1999), much less than the 10-s retention time in the test system. The comparison between experiment result and

Table 1

Mass balance calculation of water vapor in the chamber

\begin{tabular}{|c|c|c|c|c|c|c|c|c|}
\hline $\begin{array}{l}\text { Liquid } \\
\text { injection rate } \\
\text { (A) } \\
\left(\mathrm{ml} \mathrm{min} \mathrm{m}^{-1}\right)\end{array}$ & $\begin{array}{l}\text { Initial } \\
\text { temperature } \\
(\mathrm{B}) \\
T 1\left({ }^{\circ} \mathrm{C}\right)\end{array}$ & $\begin{array}{l}\text { Initial } \\
\mathrm{RH}(\mathrm{C}) \\
\%\end{array}$ & $\begin{array}{l}\text { Temperature } \\
\text { after injection } \\
(\mathrm{D}) \\
T 2\left({ }^{\circ} \mathrm{C}\right)\end{array}$ & $\begin{array}{l}\text { Measured RH } \\
\text { after injection (E) }\end{array}$ & $\begin{array}{l}\text { Mass rate of water vapor } \\
\text { before injection }(F) \\
\left(\mathrm{g} \mathrm{min}^{-1}\right)\end{array}$ & $\begin{array}{l}\text { Mass rate of water } \\
\text { vapor after injection }(G) \\
\left(\mathrm{g} \mathrm{min}^{-1}\right)\end{array}$ & $\begin{array}{l}\text { Theoretical } \\
\text { RH }(\mathrm{H})\end{array}$ & $\begin{array}{l}\text { Evaporation ratio } \\
(\mathrm{I})=(\mathrm{G}-\mathrm{F}) / \mathrm{A} \times 100 \% \\
\%\end{array}$ \\
\hline 0 & 27 & 4.8 & 27 & 4.7 & 0.105 & 0.103 & 4.8 & - \\
\hline 0.1 & 26.2 & 4.2 & 25.6 & 9 & 0.088 & 0.183 & 9.2 & 95 \\
\hline 0.2 & 26.6 & 4.9 & 25.1 & 15 & 0.105 & 0.296 & 15.5 & 95 \\
\hline 0.3 & 26.2 & 4.4 & 24.2 & 21.2 & 0.092 & 0.400 & 20.8 & 103 \\
\hline 0.4 & 26.4 & 5.3 & 23.5 & 28.6 & 0.113 & 0.520 & 28.2 & 102 \\
\hline 0.5 & 25.9 & 5.4 & 22.4 & 36.6 & 0.112 & 0.625 & 35.8 & 103 \\
\hline 0.6 & 26.3 & 4.1 & 21.7 & 43.7 & 0.087 & 0.718 & 41.8 & 105 \\
\hline 0.7 & 26.1 & 4.2 & 20.4 & 54.5 & 0.088 & 0.832 & 51.6 & 106 \\
\hline
\end{tabular}

1. Atmospheric pressure: $101 \mathrm{kPa}$.

2. Dilution air flow rate: $851 \mathrm{~min}^{-1}$.
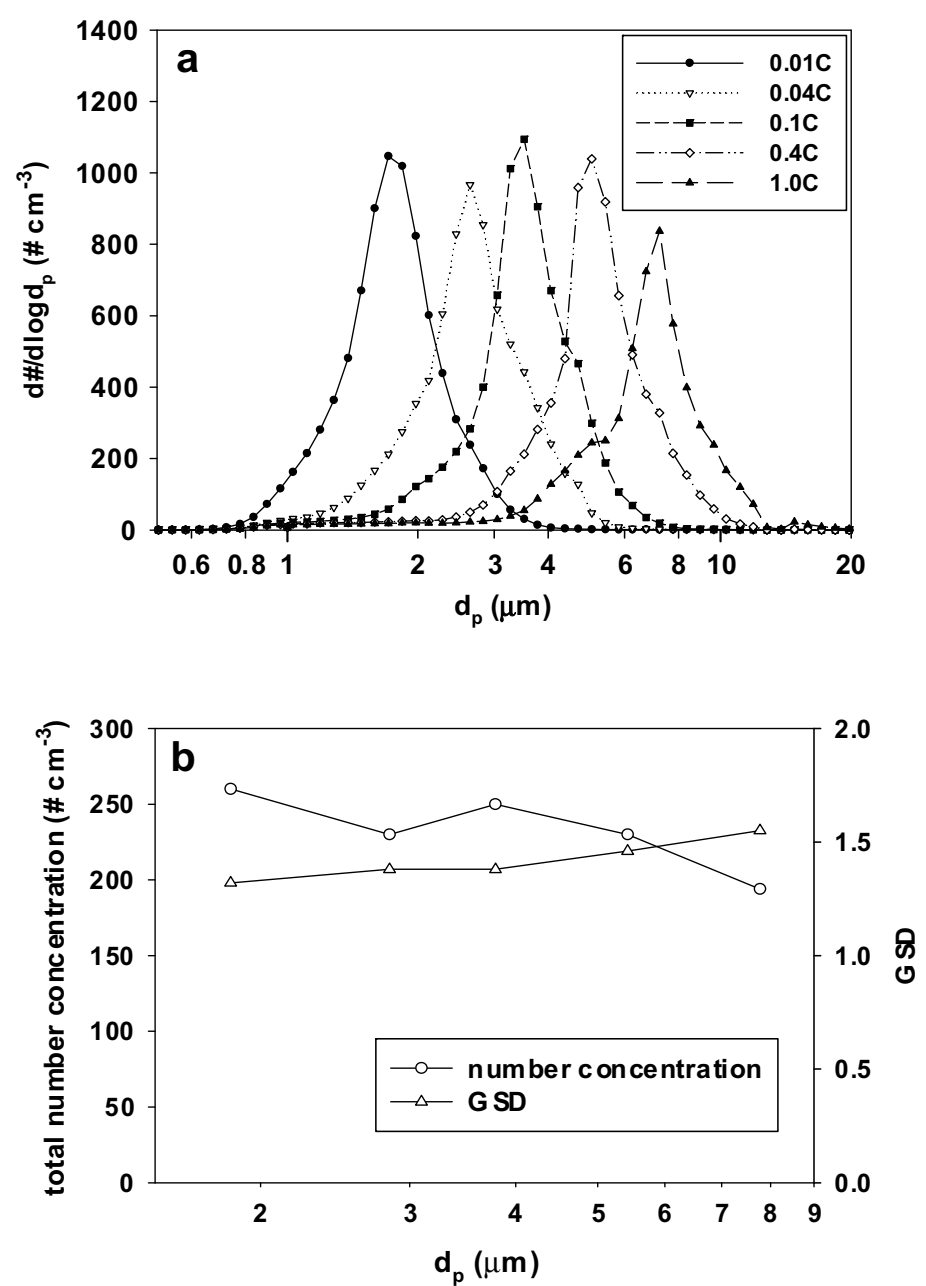

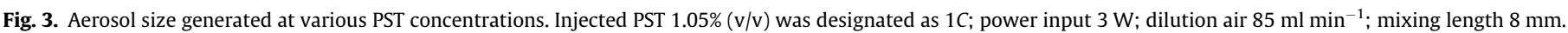


theoretical calculation confirms that the sampled aerosols are indeed fully dried. For example, the measured $\mathrm{RH}$ values were reasonably close to the theoretical ones with errors at higher liquid rate less than $6 \%$. The maximum liquid rate subsequently used was $\leqslant 0.5 \mathrm{ml} \mathrm{min}^{-1}$ to ensure that the RH of chamber will not be over $50 \%$ for the dilution air flow rate at $85 \mathrm{ml} \mathrm{min}^{-1}$.

For subsequent study, a constant power level of $3 \mathrm{~W}$ and liquid injection rate $0.5 \mathrm{ml} \mathrm{min}{ }^{-1}$ were used for all tests.

\subsection{Size at various PST concentrations}

The size distribution of aerosols at different PST concentrations at the constant flow rate is presented in Fig. 3. It is apparent that the $d_{\mathrm{p}}$ of aerosol generated varies with the PST concentration; the size increases from ca. 2 to $8 \mu \mathrm{m}$ as the PST concentration increases from $0.0105 \%$ to $1.05 \%$ (Fig. 3a). According to the regression result obtained from Fig. 3a, there exists a relationship between particle size and solute concentration, or $d_{\mathrm{p}} \sim C^{0.31}$ where $C$ is the PST concentration. Others (e.g., Mercer, 1973; Deschamps et al., 2002) have reported that the aerosol particle size is related to cubic root of non-volatile solute fraction. The deviation may be due to impurities present in the water. The theoretical diameter of residual particle $d_{\mathrm{p}}$ could be calculated from the droplet diameter $D_{\mathrm{d}}$, solute concentration $C(\mathrm{v} / \mathrm{v})$ and impurity $C_{\mathrm{i}}(\mathrm{v} / \mathrm{v})$ :

$d_{\mathrm{p}}=\left(C+C_{\mathrm{i}}\right)^{1 / 3} \times D_{\mathrm{d}}$

The exponent is $1 / 3$ if there is no impurity, i.e. $C_{\mathrm{i}}$ equals zero. When trying to approach a resultant exponent of 0.31 by regression of particle size and solute concentration, an approximate concentration of impurity $0.005 \%(\mathrm{v} / \mathrm{v})$ was obtained.

In addition, all the highest particle number distributions (Fig. 3a), total concentration and GSD (Fig. 3b) for the tested PST concentrations are nearly the same, except for the highest PST concentration (1.0C). Therefore, any changes induced by the variation of PST concentration have no substantial effect on the total aerosol concentration. The only change observed among the curves was a shift in the horizontal (diameter) axis. The results provide clear evidence that by using the two-needle system with varying PST concentrations, the desirable particle size could be obtained.

\subsection{Optimum mixing length in the nozzle}

The mixing length was the distance between the outlet of the stainless steel needle and the nozzle of the atomizer. Liquids injected from two needles were mixed in this area before being atomized. Incomplete mixing will bifurcate the pattern of the size distribution profiles because of aerosols generated from different concentrations. The test results as a function of mixing length (2-8 mm) for four different PST solute concentrations are shown in Fig. 4. At higher PST concentration $(0.5$ and $0.9 C)$, the peaks were insensitive to the mixing length (Fig. $4 a$ and b). However, at low concentrations, e.g., at $0.1 C$, the peaks experienced bifurcation if the mixing length was not long enough. A longer mixing length would yield a sharp peak. Consequently, a mixing length of 6 $\mathrm{mm}$ was selected for the subsequent experiments.

\subsection{Bimodal distribution}

Particles in ambient air are usually distributed bimodally even tri-modally including both fine and coarse particles. Thus, generation of bimodal particles for different applications is of importance. In the present study, bimodal distribution can be easily generated by alternating the PST concentrations. For example, for the cycle of $20 \mathrm{~s}$, the $0.01 \mathrm{C}$ concentration was used during the $1 \mathrm{st} 10 \mathrm{~s}$, with the next $10 \mathrm{~s}$ of the only PST solution (1C); the cycle was then

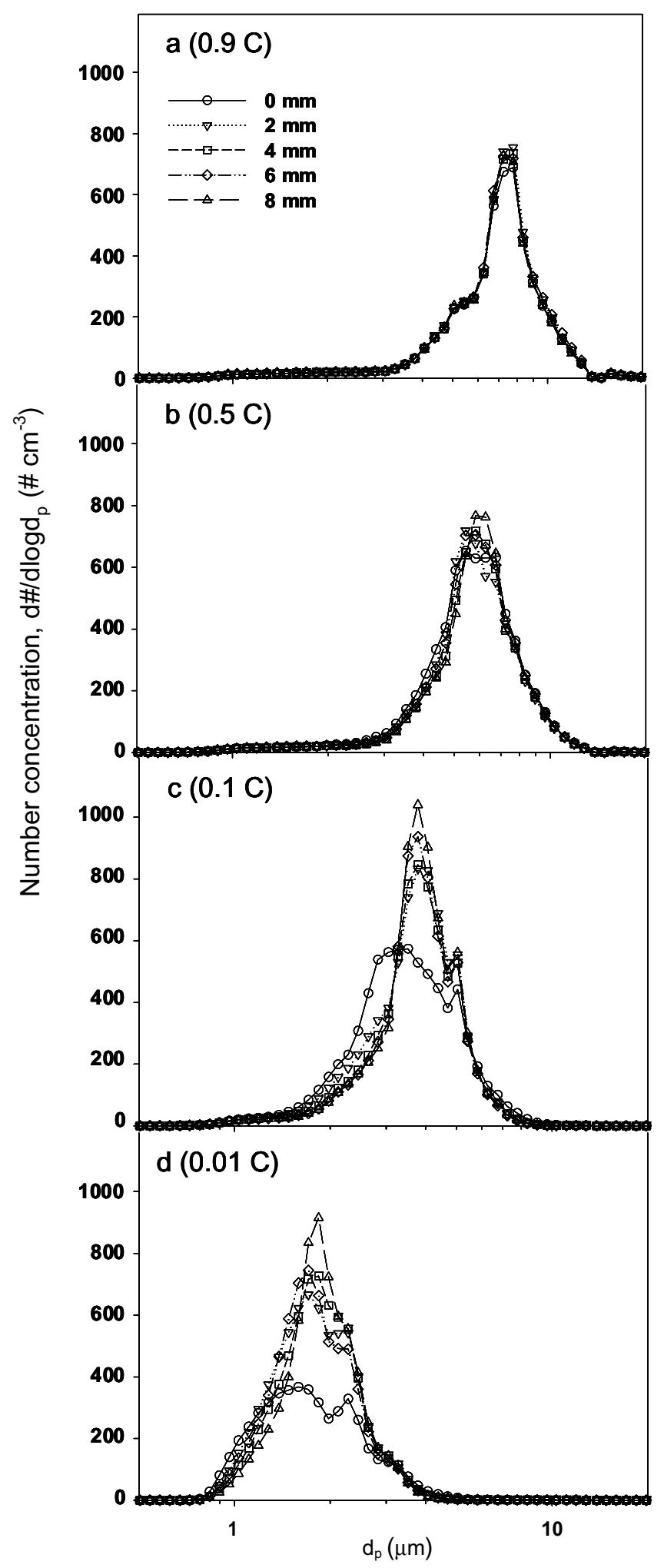

Fig. 4. Test of optimum mixing length in the nozzle. Injection PST $1.05 \%(\mathrm{v} / \mathrm{v})$; power input $3 \mathrm{~W}$; dilution air $85 \mathrm{ml} \mathrm{min}^{-1}$.

repeated. The observed bimodal results for sampling time of $300 \mathrm{~s}$ (a total of 15 cycles for alternating interval $10 \mathrm{~s}$ ) are illustrated in Fig. 5. A long alternating interval (10 s for changing PST concentration in Fig. 5a) yields two distinct peaks far apart from each other (Fig. 5c). Conversely, if the time interval was short, 
a. alternating internal $10 \mathrm{~s}$

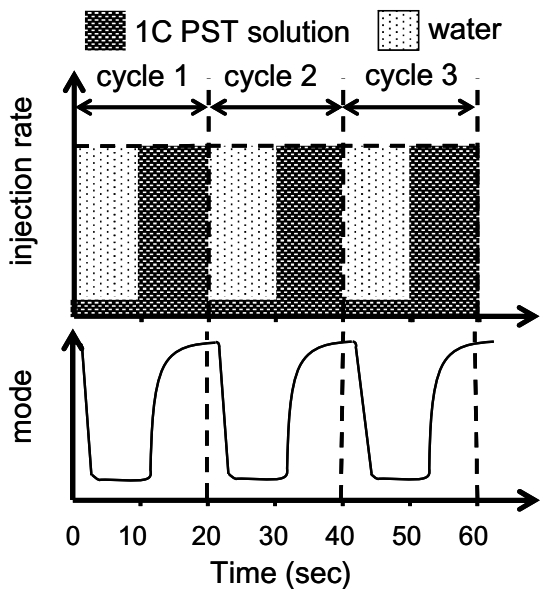

b. alternating internal $3 \mathrm{~s}$

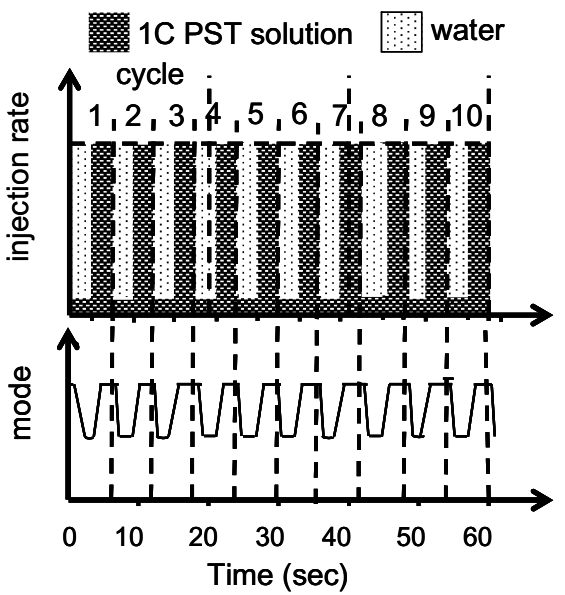

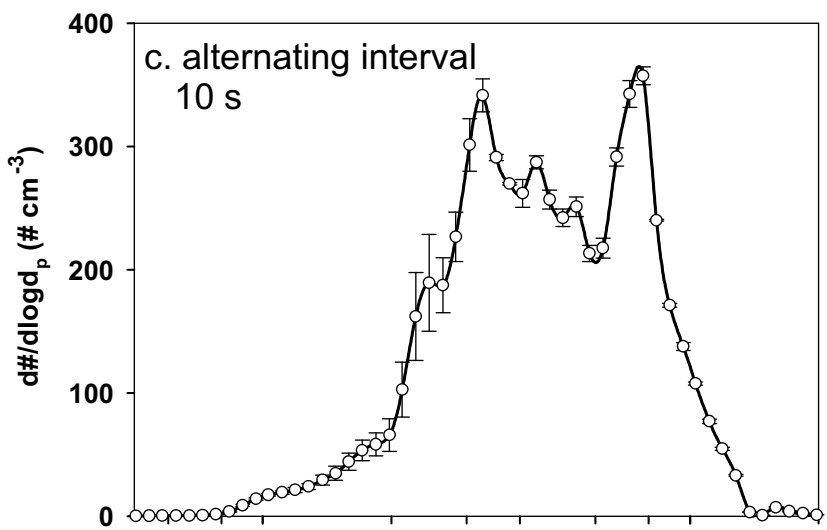

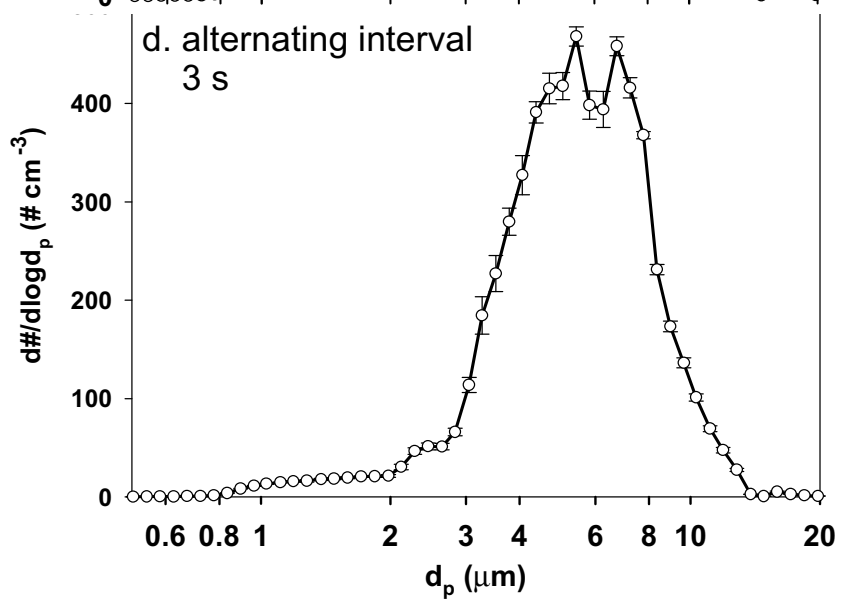

Fig. 5. Generation of bimodal particle distribution with an alternating interval of $10 \mathrm{~s}$ and $3 \mathrm{~s}$.

e.g. $3 \mathrm{~s}$ (Fig. 5b), two alternating liquids would not have ample time for a complete mixing resulting in the unresolved peaks (Fig. 5d). In short, the bimodal distribution test showed that the minimum time for each step should not less than $3 \mathrm{~s}$.

\subsection{Varying size distribution}

In many applications, such as investigating filter cake characteristic and pressure drop of filtering device, one of the interesting conditions is size distribution under specific size ranges. This can be achieved in the present study with aerosol size ranging from
3-8 $\mu \mathrm{m}$ generated by a five-step combination (case a in top Fig. 6 ). The programmed steps used were: $1 C$ for $12 \mathrm{~s}$, followed by $0.3 C$ for $5 \mathrm{~s}$, then $0.1 \mathrm{C} 4 \mathrm{~s}, 0.02 \mathrm{C} 3 \mathrm{~s}$ and eventually $0 \mathrm{C}$ (water only) for $6 \mathrm{~s}$, with a total cycle time of $30 \mathrm{~s}$. Results in Fig. 6a were the average values of 10 repeated test data (total of $300 \mathrm{~s}$ ). In addition to aerosols with varying size, the number concentrations within this size range $(3-8 \mu \mathrm{m})$ is similar, from $200-300 \# \mathrm{~cm}^{-3}$. Although the size distribution pattern was not steady for each specific time (e.g., each step), the average size distribution pattern over the cycle time, however, was relatively reproducible. It is noted that a 30-s cyclic time was used in the APS to coincide with 
total cycle time: $30 \mathrm{sec}$

\begin{tabular}{cllllll} 
case & step number & 1 & 2 & 3 & 4 & 5 \\
\hline \multirow{2}{*}{ a } & PST concentration & $1 \mathrm{C}$ & $0.3 \mathrm{C}$ & $0.1 \mathrm{C}$ & $0.02 \mathrm{C}$ & $0 \mathrm{C}$ \\
& step duration, s & 12 & 5 & 4 & 3 & 6 \\
\hline \multirow{2}{*}{ b } & PST concentration & $1 \mathrm{C}$ & $0.6 \mathrm{C}$ & $0.3 \mathrm{C}$ & $0.02 \mathrm{C}$ & $0 \mathrm{C}$ \\
& step duration, s & 15 & 4 & 4 & 3 & 4
\end{tabular}

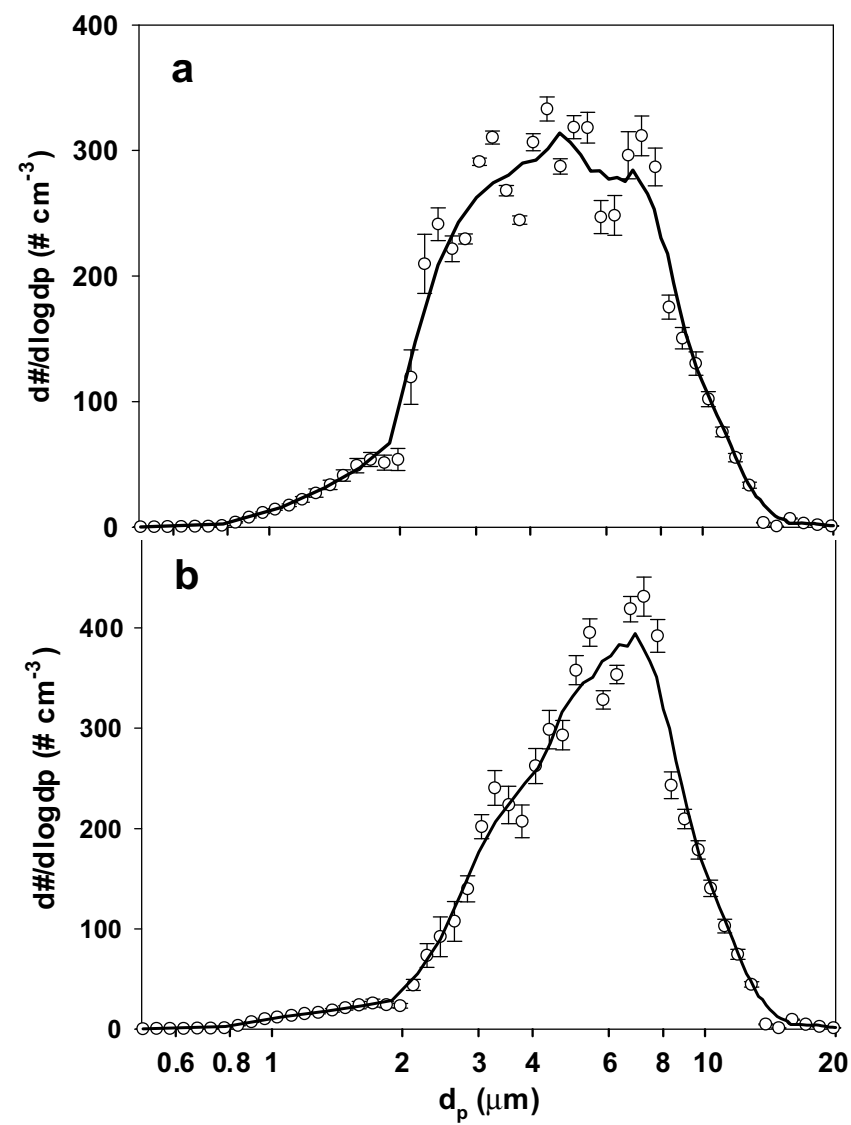

Fig. 6. Illustrations of aerosols generated by five-step combinations. (a) Varying size distribution; (b) skew distribution.

the aerosol generating cycles. This would reduce the error caused by unmatched cycle time between generation system and measure instrument.

Although 5-step approach shown in Fig. 6a may not yield a uniform number concentration, it is envisioned that more steps may be needed for rendering relatively same particle number concentration.

\subsection{Lognormal distribution skewed to the right}

For most particle collection devices or personal protection equipments, particle removal efficiency is a function of particle size. Further, an error in efficiency calculation may be encountered if the number of the testing aerosols was not high enough. In particular, if the number of the aerosols was distributed more in the size fraction of a lesser capturing efficiency (smaller size), the error could be compounded. Consequently, it is necessary to generate aerosols with log-normal distribution skewed to the larger size to minimize the errors. This can be done with a similar 5-step liquid injection as shown in the programmed steps shown by case b of Fig. 6 . The particle number concentration for $8 \mu \mathrm{m}$ is approx- imately three times as high as for that of $3 \mu \mathrm{m}$. Thus, by gradually changing the PST concentration, the desirable size distribution pattern can be obtained.

\section{Conclusions}

The generation system developed in this study has successfully demonstrated a steady and reproducible aerosol generation. Several different particle size distributions, such as unimodal, bimodal, varying size and skew distribution can be easily generated. The uniqueness of the proposed system is the use of two-needle systems for adjusting PST concentration by mixing with the water. The application of the developed system can be used as a testing aerosol source for the evaluation of particle removal efficiency which is sensitive to the particle loading on the filter. The filter cake formed by mono-dispersed particles is certainly not the same as by poly-dispersed particles. Traditional aerosol generation facilities could not simulate the actual size distribution of particles. Consequently, the system developed in the present study provides an opportunity to simulate the particle distribution in the real world. Again, desirable size distribution of particle simulating from 
work place near specific particle source or different times/locations of atmospheric conditions can be generated with the developed system.

\section{Acknowledgment}

This work was carried out with the financial support from the National Science Council of Taiwan (NSC91-2621-Z-002-025).

\section{References}

Baron, P.A., Willeke, K., 2001. Aerosol Measurement: Principles, Techniques, and Applications. John Wiley, New York.

Deschamps, F.S., Baillet, B., Chaminade, P., 2002. Mechanism of response enhancement in evaporative light scattering detection with the addition of triethylamine and formic acid. Analyst 127, 35-41.

Endo, Y., Chen, D.R., Pui, D.Y.H., 1998. Bimodal aerosol loading and dust cake formation on air filters. Filtr. Separat. 35, 191-195.

Heist, D.K., Richmond-Bryant, J., Eisner, A., Corner, T., 2003. Develop of a versatile aerosol generation system for use in a large wind tunnel. Aerosol. Sci. Tech. 37 293-301.

Hinds, W.C., 1999. Aerosol Technology. John Wiley, New York.

Kim, J.T., Chang, J.S., 2005. Generation of metal oxide aerosol particles by a pulsed spark discharge technique. J. Electrostat. 63, 911-916.

Lee, D.W., Cheng, M.D., 2006. Particle generation by ultraviolet-laser ablation during surface decontamination. J. Air Waste Manage. 56, 1591-1598.

Mercer, T.T., 1973. Aerosol Technology in Hazard Evaluation. Academic Press, New York.

Nichols, W.T., Malyavanatham, G., Henneke, D.E., O'brien, D.T., Becker, M.F., Keto, J.W., 2002. Bimodal nanoparticle size distributions produced by laser ablation of microparticles in aerosols. J. Nanopart. Res. 4, 423-432.
Oberdorster, G., Gelein, R., Ferin, J., Weiss, B., 1995. Association of particulate air pollution and acute mortality: involvement of ultrafine particles. Inhal. Toxicol. 71, 111-124.

Pagel, J., Gudmundsson, A., Gustavsson, E., Asking, L., Bohgard, M., 2005. Evaluation of aerodynamic particle sizer and electrical low-pressure impactor for unimodal and bimodal mass-weighted size distributions. Aerosol Sci. Tech. 39, 871-887.

Park, K.S., Lee, B.W., Choi, M., 1999. An analysis of aerosol dynamics in the modified chemical vapor deposition. Aerosol Sci. Tech. 31, 258-274.

Peters, A., Wichmann, E., Tuch, T., Heinrich, J., Heyder, J., 1997. Respiratory effects are associated with the number of ultrafine particles. Am. J. Resp. Crit. Care 155, 1376-1383.

Shi, J.P., Evans, D.E., Khan, A.A., Harrison, R.M., 2001. Sources and concentration of nanoparticles ( $<10 \mathrm{~nm}$ diameter) in the urban atmosphere. Atmos. Environ. 35, 1193-1202.

Smith, R.L., Spitzner, D., Kim, Y., Fuentes, M., 2000. Threshold dependence of mortality effects for fine and coarse particles in Phoenix, Arizona. J. Air Waste Manage. 50, 1367-1379.

Veranth, J.M., Gelein, R., Oberdorster, G., 2003. Vaporization-condensation generation of ultrafine hydrocarbon particulate matter for inhalation. Aerosol Sci. Tech. 37, 603-609.

Vette, A.F., Rea, A.W., Lawless, P.A., Rodes, C.E., Evans, G., Highsmith, V.R., Shelton, L., 2001. Characterization of indoor-outdoor aerosol concentration relationships during the Fresno PM exposure studies. Aerosol. Sci. Tech. 34, 118-126.

Wehner, B., Bermili, W., Gnauk, T., Wiedensohler, A., 2002. Particle number size distributions in a street canyon and their transformation into the urban-air background: measurements and a simple model study. Atmos. Environ. 36, 2215-2223.

Weigle, J.C., Luhrs, C.C., Chen, C.K., Perry, W.L., Mang, J.T., Nemer, M.B., Lopez, G.P., Philips, J., 2004. Generation of aluminum nanoparticles using an atmospheric pressure plasma torch. J. Phys. Chem. B 108, 18601-18607.

Zhou, J.B., Wang, T.G., Hwang, Y.B., Mao, T., Zhong, N.N., 2005. Size distribution of polycyclic aromatic hydrocarbons in urban and suburban sites of Beijing, China. Chemosphere 61, 792-799.

Zhu, Y., Hinds, W.C., Kim, S., Shen, S., Sioutas, C., 2002. Study of ultrafine particles near a major highway with heavy-duty diesel traffic. Atmos. Environ. 36, 43234335. 